\title{
APLICAÇÃO DO OPERADOR DE FRAGMENTAÇÃO ASSIMÉTRICA (FA) NA CARACTERIZAÇÃO DE CONTROLES GEOMORFOLÓGICOS EM RESERVATÓRIOS HIDROELÉTRICOS
}

\author{
ARCILAN T. ASSIREU ${ }^{1}$, JOÃO A. LORENZZETTI ${ }^{1}$, EVLYN M. L. M. NOVO $^{1}$, JOSÉ L. STECH $^{1}$, \\ CLÁUDIA Z. F. BRAGA ${ }^{1,2} \&$ IVAN B. TAVARES DE LIMA ${ }^{1}$
}

\begin{abstract}
ASYMMETRICAL FRAGMENTATION OPERATOR (FA) APPLIED TO CHARACTERIZE GEOMORPHOLOGIC CONTROLS ON HYDROELECTRICAL RESERVOIRS This paper proposes the use of the Asymmetrical Fragmentation Operator (FA) to characterize geomorphologic controls affecting hydroelectrical reservoirs. Landsat-TM images were used to map reservoirs flooded surface. The FA operator was applied to vector files describing reservoirs shape to compute the average FA for each reservoir. The reservoir database was then classified according to reservoirs hydrographic basin and reservoirs size. The FA values were compared to the Shoreline Development Index (D) and to the reservoirs primary productivity data available in the literature. Results show that the FA is able to detect high-resolution geomorphologic features, which are not detected by D. Preliminary results show also that there is a significant relationship between FA and the primary productivity. This fact, however, does not hold for D. Moreover, FA showed no sensitivity to reservoirs size, being more responsive to their position in the cascade system, and therefore to the hydrographic basin geomorphology.
\end{abstract}

Keywords: Asymmetrical Fragmentation Operator, geomorphologic controls, hydro electrical reservoirs, hydrographic basin, Shoreline Development Index

\begin{abstract}
Resumo Este trabalho propõe o uso do Operador de Fragmentação Assimétrica (FA) para a caracterização de controles geomorfológicos que afetam reservatórios hidroelétricos. A superfície alagada pelos reservatórios foi determinada a partir de imagens digitais do sensor TM-Landsat. O Operador de Fragmentação Assimétrica foi aplicado ao vetor descritor da superfície alagada de cada reservatório permitindo o cálculo de seu FA médio. Os reservatórios foram então classificados por bacia hidrográfica e dimensão da superfície alagada. Os valores de FA foram cotejados com o índice de desenvolvimento das margens (D) dos reservatórios e com dados de produtividade primária disponíveis na literatura. Os resultados indicam que o FA tem a capacidade de detectar, em alta resolução, estruturas geomorfológicas que passam desapercebidas ao índice D. Análises preliminares indicaram haver relação entre o grau de fragmentação e a produtividade primária nos reservatórios. Os resultados indicaram que ao contrário do D, o FA é pouco sensível à área do reservatório, tendo respondido mais à sua posição na cascata, e consequientemente ao arcabouço geomorfológico.
\end{abstract}

Palavras-chave: Operador de Fragmentação Assimétrica, controles geomorfológicos, reservatórios hidroelétricos, bacia hidrográfica, índice de desenvolvimento das margens

INTRODUÇÃO Os rios do Brasil, sob o ponto de vista fisiográfico, podem ser classificados como rios de planície e baixos platôs e rios de planalto. Os primeiros, via de regra, possuem um perfil longitudinal de baixo gradiente, isto é com pequeno desnível entre as nascentes e a barragem. Possuem poucas corredeiras e cachoeiras de modo que a velocidade do escoamento da água é basicamente função de seu volume, e, portanto, da dimensão da bacia de captação e do regime pluviométrico regional.

Os rios de planalto, por sua vez, apresentam grandes desníveis entre as nascentes e as barragens, e possuem grande potencial hidráulico. No Brasil a Bacia do Paraná e seus afluentes, Parnaíba, Grande, Tietê, Paranapanema e Iguaçu, apresentam desníveis superiores a $1000 \mathrm{~m}$. Outros importantes rios de planalto são o Tocantins-Araguaia e o São Francisco, cujos desníveis das nascentes à foz também se encontram entorno de $1000 \mathrm{~m}$.

O suprimento energético do Brasil se concentra basicamente na hidreletricidade. Segundo Müller (1996) a produção constante de energia depende de dois elementos essenciais: 1) um reservatório de acumulação capaz de reter águas no período chuvoso para uso no período de estiagem; 2) um sistema de controle, nas turbinas, para ajustar o caudal às demandas de energia.
A área do reservatório representa a superfície do terreno inundada pelo represamento da água de um rio, na cota correspondente ao nível máximo de operação. Os reservatórios se caracterizam pela superfície inundada e pela capacidade de geração de energia. A capacidade de um reservatório depende do volume ativo de água, que é definido pelos níveis máximos e mínimos operativos. Os fatores que favorecem ou dificultam o aproveitamento hidrelétrico são controlados pelas características fisiográficas de uma dada região, uma vez que estas determinam a vazão do rio (velocidade de escoamento da água) e a altura de queda da água. A morfometria e o substrato geológico das bacias que contêm os reservatórios são fatores determinantes nas interações entre os ecossistemas terrestres e aquáticos, que influenciam na qualidade de suas águas. A geomorfologia das bacias se reflete nos eventos físicos, químicos e biológicos que ocorrem nos reservatórios formados em seu interior.

As características topográficas e altimétricas controlam o potencial hidrelétrico de uma dada bacia hidrográfica (Müller 1996). O rio Amazonas e todos os seus afluentes possuem uma vazão média anual de $250 \mathrm{mil} \mathrm{m}^{3} \mathrm{~s}^{-1} \mathrm{e}$ um potencial hidrelétrico de $54 \times 10^{6} \mathrm{~kW}$ ano ${ }^{-1}$. O rio Paraná, em Itaipu, tem uma vazão em

1- Programa Processos da Hidrosfera - HIDRO - Divisão de Sensoriamento Remoto - INPE - Av, dos Astronautas 1758, Jardim da Granja, São José dos Campos, SP, CEP: 12227-010 - E-mails: (arcilan, evlyn, stech, loren, ivan)@ltid.inpe.br

2 - in memórian 
torno de apenas $9 \mathrm{mil} \mathrm{m}^{3} \mathrm{~s}^{-1}$ (27 vezes menor) com um potencial hidrelétrico de cerca de $30 \times 10^{6} \mathrm{~kW}$ ano ${ }^{-1}$ ( 1,8 vezes menor). Essa variabilidade regional faz com que o impacto ambiental dos diferentes reservatórios hidrelétricos varie amplamente. Recentemente, uma série de índices tem sido propostos para avaliar o impacto ambiental de uma barragem. Dentre esses índices, um dos mais utilizados é a relação potência/área inundada.

Um dos parâmetros mais utilizados em limnologia para descrever a morfometria dos corpos d'água é o índice $\mathrm{D}$, de desenvolvimento das margens (Wetzel 1975). Esse índice representa a razão entre o perímetro do corpo d’água $(L)$ em relação ao comprimento da circunferência de um círculo com área equivalente à do corpo d’água.

Reservatórios circulares tendem a ter valores próximos a 1, enquanto que os alongados, ou com padrão dendrítico tendem a ter valores que se distanciam de 1. Quanto maior o índice de desenvolvimento das margens, maior é a probabilidade de desenvolvimento de comunidades litorâneas e de interferência da bacia de captação imediata nas propriedades locais do corpo d'água.

Os valores de $\mathrm{D}$, entretanto, são descritores muito simplificados da complexidade dos padrões espaciais dos reservatórios; complexidade essa derivada da interação entre o projeto de engenharia adotado (altura entre a fundação e crista, comprimento de crista, volume) e as características topográficas das bacias hidrográficas em que eles se inserem.

As bacias de drenagem se diferenciam em função dos padrões de drenagem (Christofoletti 1986), que por sua vez são influenciados pela: disposição e resistência das diferentes rochas, declividade, amplitude altimétrica e história geológica e geomorfológica local.

Sob o ponto de vista puramente geométrico, os padrões de drenagem podem ser classificados em: dendrítico (típico de regiões de estruturas sedimentares horizontais com rochas de resistência uniforme); treliça (típico de rios principais conseqüentes com afluentes subseqüentes, obseqüentes e resseqüentes) (Christofoletti 1986); paralelo (típico de regiões com forte controle estrutural e vertentes íngremes); radial (centrífuga, com rios conseqüentes divergentes a partir do interflúvio e centrípeta, com rios convergentes típicos de depressões topográficas).

Além de se diferenciarem quanto ao padrão geométrico, as bacias também se diferenciam numericamente no tocante à densidade de drenagem, relação de bifurcação, gradiente, índice de forma da bacia, coeficiente de manutenção, amplitude altimétrica, coeficiente orográfico, relação de relevo e índice de rugosidade (Christofoletti 1986).

Como conseqüência dessa ampla possibilidade de variabilidades, o represamento de um rio pode resultar em lagos de formas e complexidade variáveis em diversas escalas. Essa complexidade, teoricamente, pode ser traduzida em termos numéricos através de índices derivados de métodos de análise de padrões de gradientes (Gradient Pattern Analyses) introduzidos por Rosa et al. (1998).

Portanto o objetivo desse estudo é avaliar o uso dos métodos de análise de gradiente, particularmente, o Operador de Fragmentação Assimétrica (FA) na caracterização das propriedades morfométricas dos reservatórios hidrelétricos brasileiros.

FUNDAMENTAÇÃO TEÓRICA O Operador de Fragmentação Assimétrica é uma técnica eficiente para caracterizar padrões de variabilidade espacial e faz parte do método de análise de padrões dos campos gradientes (Gradient Pattern Analysis GPA, introduzido por Rosa et al. (1998)). O pressuposto adotado no desenvolvimento do GPA é o de que a complexidade de um padrão espacial é caracterizada pela sua falta de simetria e pelo seu grau de fragmentação. Essas propriedades do padrão (falta de simetria e fragmentação) podem ser resumidas no Operador de Fragmentação Assimétrica (FA). Padrões simétricos apresentam valores de Fa iguais ou próximos a zero. A partir da análise de aproximadamente 200 simulações de padrões, Rosa et al. (1998) e Rosa et al. (1999) concluíram que o aumento de FA corresponde a um aumento da quantidade e da extensão de contornos e de estruturas finas em diferentes padrões. A Figura 1 ilustra os resultados das simulações de Rosa et al. (1998). Pode-se observar que à medida que o padrão espacial se torna mais complexo e que há um aumento da variabilidade de pequena escala, o valor de FA aumenta.

Este operador (FA) propicia uma investigação da complexidade espaço-temporal contida na série espaço-temporal. A técnica GPA foi originalmente desenvolvida para operar com matrizes. Assireu et al. (2002) apresentaram uma adaptação que possibilitou a aplicação desta técnica a séries espaço-temporais unidimensionais. Por não se basear em propriedades estatísticas da série, mas somente nas propriedades locais das simetrias do padrão gradiente, o método apresenta a importante propriedade de ser menos dependente do comprimento da série, quando comparado às técnicas estatísticas convencionais. Isto abre a possibilidade ao método de localizar, ao longo de entornos, quais são as regiões com maior complexidade morfométrica. Alguns detalhes sobre este método serão agora apresentados e maiores detalhes podem ser obtidos em Rosa et al. (1999) e Assireu et al. (2002).

A análise baseada no Fator de Assimetria (FA) do padrão de gradientes consiste em gerar campos vetoriais, a partir de matrizes numéricas (Fig. 2). Por conveniência metodológica aplicada às estruturas complexas, os vetores simétricos são removidos e portanto apenas os vetores assimétricos são mantidos. Pela análise da Figura 2 percebe-se que, embora a matriz relativa a Figura 2(c) corresponda a um processo mais complexo (mais irregular) quando comparado ao apresentado na Figura 2(b), a simples comparação entre o número de vetores oriundos do campo gradiente (V) e o número de vetores assimétricos (L) não permitiria uma separabilidade dos diferentes processos representados por estas matrizes. Devido a isto, há necessidade de uma segunda operação que permita distinguir entre estes campos gradientes.

Dada uma distribuição cartesiana $\mathrm{P}$ com $\mathrm{p}$ pontos, o processo de união destes pontos através de linhas usando como critério a necessidade dos vértices dos triângulos resultantes estarem sempre

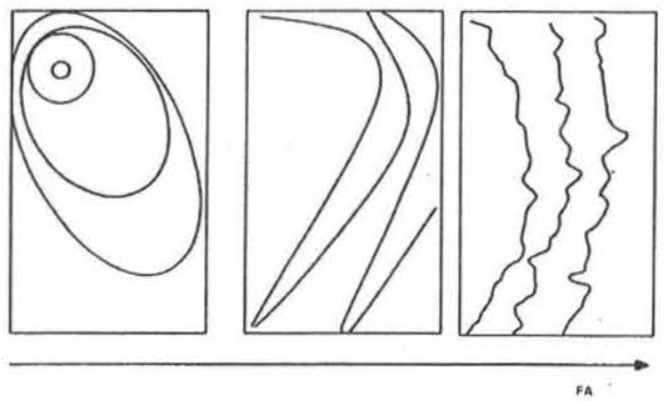

Figura 1 - Resposta teórica do FA à complexidade do padrão espacial Adaptado de Rosa et al. 1998. 
em conexão com estes pontos é conhecido como Triangulação de Delaunay (maiores detalhes vide Adelsbrunner 1993). Também faz parte do critério o não cruzamento das linhas que unem os pontos (Fig. 3). Note que agora é possível distinguir as matrizes, mesmo estas tendo iguais valores de V e L. O número de linhas (I) utilizado para unir, via triangulação de Delaunay, os centros de cada vetor, é diferente. Portanto, com a quantidade I é possível distinguir diferentes matrizes quanto a sua correspondência em termos de complexidade, já que I é diretamente proporcional ao nível de desordem espacial (complexidade) do campo gradiente. $\mathrm{O}$ valor numérico utilizado para representar este campo de assimetria é:

$$
\mathrm{FA}=(\mathrm{I}-\mathrm{L}) / \mathrm{L} \quad(\mathrm{I} \geq \mathrm{L}>0)
$$

Como comentado, esta técnica foi originalmente desenvolvida para tratar campos bidimensionais representados através de matrizes numéricas. Com o intuito de estender as aplicações do método para séries unidimensionais, Assireu et al. (2002) fizeram a seguinte adaptação: cada nove pontos da série são convertidos em uma matriz $3 \times 3$ e o método é, desta forma, aplicado ao longo da série. Esta série pode ser, por exemplo, a componente $\mathrm{x}$ ou y do entorno de reservatórios. Um valor médio, considerando cada um dos FAs obtidos ao longo da série é gerado. A figura 4 exemplifica o método. Um exemplo de uma série unidimensional com nove pontos (Fig. 4a) que é convertida em uma matriz 3×3 (Fig. 4b) e finalmente os campos de gradiente e de triangulação são gerados (Figs. 4c e 4d respectivamente). A escolha de se utilizar matrizes $3 \times 3$ deve-se à possibilidade das análises serem feitas na melhor janela de resolução e sem comprometimento da robustez do método. Por exemplo, uma série de dados que representa o entorno de um reservatório obtido a partir de uma imagem Landsat em resolução de $20 \mathrm{~m}$, gera um índice (FA) a cada $180 \mathrm{~m}$ ao longo do entorno.

MÉTODOS Tendo em vista que a forma de um reservatório pode ser representada por um vetor cuja complexidade traduz seus diferentes padrões espaciais, o método GPA foi aplicado a dados vetoriais disponíveis para 124 reservatórios hidrelétricos. A Tabela 1 resume o tamanho médio dos reservatórios dos principais rios brasileiros. A superfície alagada pelos mesmos foi determinada a partir de imagens digitais do sensor TM-Landsat.

A primeira fase do trabalho consistiu na obtenção de uma matriz

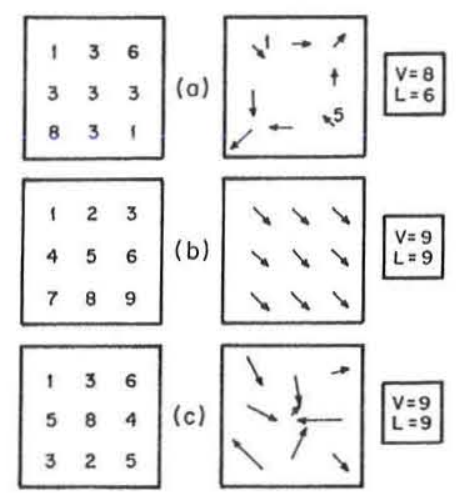

Figura 2 - Exemplo de matrizes representativas de campos vetoriais assimétricos. (a): seis vetores assimétricos (note que os vetores 1 e 5 são simétricos), (b) e (c): todos os vetores são assimétricos (Fonte: Rosa et al. (1999)). de dados com a distribuição dos reservatórios por bacia hidrográfica e seus posicionamentos ao longo dos rios. Esse banco de dados é composto pelas seguintes informações: a) fornecidas pelo IBGE: Hidrografia (rios permanentes, temporários e áreas inundáveis), Divisão Estadual, Divisão Municipal, Estradas, Delimitação das Bacias Hidrográficas Brasileiras, Delimitação das Sub Bacias Hidrográficas Brasileiras; b) extraídas das imagens TM/Landsat: dados vetoriais e temáticos dos 124 reservatórios mapeados; c) dados fornecidos pela ANEEL: dados cadastrais com a localização dos reservatórios e nome do empreendimento.

Com base nesse banco de dados foi possível determinar a distribuição dos reservatórios ao longo de um rio ou sub-bacia hidrográfica (Tabela 2).

Paralelamente à classificação dos reservatórios por bacia hidrográfica, aplicou-se o operador de Fragmentação Assimétrica aos dados vetoriais representativos da forma de cada reservatório. Devido à grande amplitude de variação no tamanho dos reservatórios, foram adotadas duas estratégias de cálculo do FA médio. Os valores de FA foram obtidos a partir dos dados brutos e também a partir destes dados filtrados por um filtro do tipo média móvel de 10 pontos.

Para concentrar as análises em apenas uma das componentes direcionais do reservatório, foi efetuada uma rotação do eixo segundo a direção de máxima variância da distribuição. A figura 5 ilustra o efeito da aplicação do filtro e da rotação sobre os eixos segundo a direção de máxima variância.

Os valores médios de FA para cada reservatório foram então convertidos para a escala decibel $\left\{10 \log _{10}(\mathrm{FA})\right\}$. Segundo Assireu et al. (2002) uma melhor distinção dos padrões espaciais pode ser

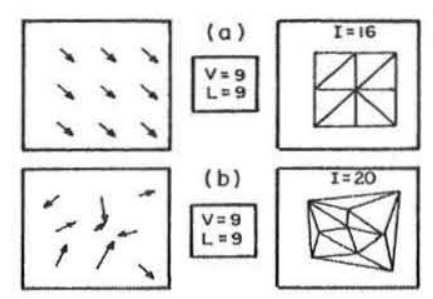

Figura 3 - Campo de triangulação para as matrizes $(b) e$ (c) da Figura 2 (Fonte: Rosa et al. (1999)).

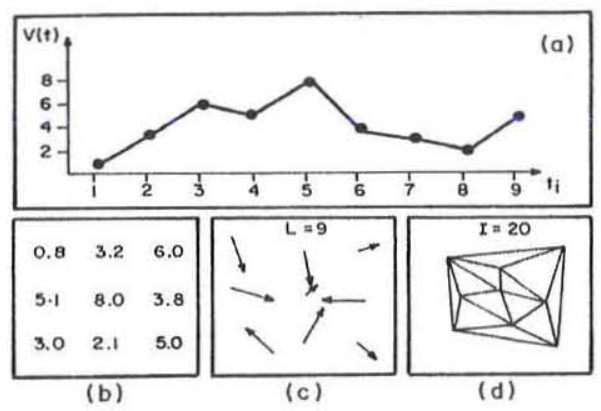

Figura 4 - (a) um típico padrão de variabilidade extraído de uma série relativa a uma variável genérica $V(t)$, (b) sua correspondente matriz; (c) correspondente campo gradiente (nove vetores assimétricos) $e(d)$ campo de triangulação com 20 linhas conectoras (Fonte: Assireu et al. (2002)). 
obtida ao se considerar os valores de FA em escala decibel. Esta transformação é importante porque o desvio padrão dos FA médios é da ordem de 0,002 , o que torna um valor de FA igual a 1.000 , por exemplo, significativamente diferente do valor de FA igual a 1,005. Este fato confere grande sensibilidade ao FA, fazendo desse operador um eficiente método de distinção de feições. A transformação para a escala decibel amplifica essa capacidade de distinção.

\section{RESULTADOS E DISCUSSÕES O efeito da bacia} hidrográfica sobre o FA dos reservatórios hidroelétricos $\mathrm{A}$ Tabela 3 resume os valores médios de FA e D para os reservatórios

Tabela 1 - Área média dos reservatórios das usinas hidroelétricas. Valores entre parênteses indicam o número de reservatórios em cada bacia.

\begin{tabular}{lcc}
\hline \multicolumn{1}{c}{ Bacia hidrográfica } & $\begin{array}{c}\text { Área média } \\
\left(\mathrm{km}^{2}\right)\end{array}$ & $\begin{array}{c}\text { Coeficiente } \\
\text { de variação } \\
\left(\mathrm{km}^{2}\right)\end{array}$ \\
\hline Atlântico Sudeste & $3,23(10)$ & 148,65 \\
Rio Paranapanema & $162,05(9)$ & 115,96 \\
Rio Iguaçu & $73,07(5)$ & 105,62 \\
Rio Grande & $120,16(10)$ & 179,90 \\
Bacia Lagunar (RS) & $52,46(5)$ & 188,47 \\
Rio Paraná (canal principal) & $1429,19(4)$ & 78,37 \\
Rio Parnaíba & $351,60(2)$ & 83,40 \\
Rio Doce & $3,18(6)$ & 76,89 \\
Rio São Francisco & $813,38(9)$ & 185,00 \\
Rio Parába do Sul & $28,05(13)$ & 192,28 \\
Rio Tocantins & $1070,48(4)$ & 132,93 \\
Rio Amazonas & $1738,11(3)$ & 135,39 \\
\hline
\end{tabular}

Tabela 2 - Relação de Reservatórios por Bacia Hidrográfica.

\begin{tabular}{lc}
\hline \multicolumn{1}{c}{ Reservatório } & Bacia do Rio São Francisco \\
\hline Gafanhoto & Alto São Francisco \\
Itaparica & Médio São Francisco \\
Moxotó & Médio São Francisco \\
Paulo Afonso I II III & Médio São Francisco \\
Paulo Afonso IV & Médio São Francisco \\
Sobradinho & Médio São Francisco \\
Três Marias & Alto São Francisco \\
Xingó & Baixo São Francisco \\
\hline
\end{tabular}

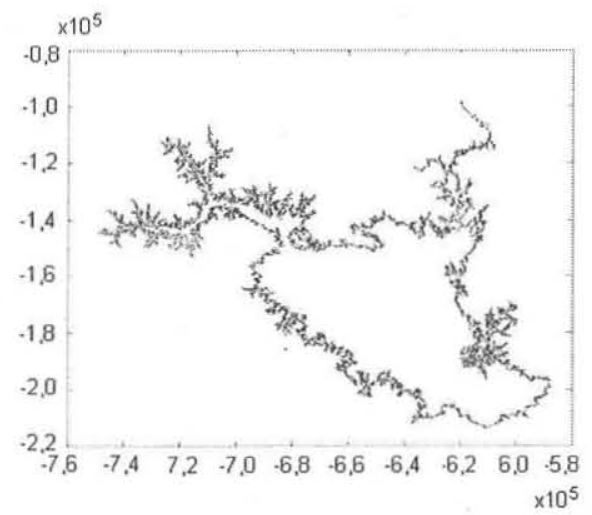

agrupados por bacia hidrográfica

Um aspecto que chama a atenção na análise desses dados é o aumento do CV de FA dos reservatórios em cerca de $54 \%$ das bacias hidrográficas em relação ao $\mathrm{CV}$ de D. Esse efeito é observado nas bacias dos rios Iguaçu, Tietê, Grande, Parnaíba, Doce, Paraíba do Sul, Tocantins e Amazonas. O caso mais crítico ocorre na bacia do Rio Tocantins, onde o coeficiente de variação dos valores de FA dos 4 reservatórios nela localizados é superior a $1000 \%$, enquanto o coeficiente de variação de D é de apenas $60,6 \%$. Isto significa que o FA está captando variações internas nos padrões dos reservatórios não perceptíveis pelo índice de desenvolvimento das margens. A grande dispersão do FA na Bacia do Tocantins está relacionada ao reservatório de São Domingos, que é um pequeno reservatório, localizado no alto curso de um dos afluentes do rio Tocantins.

A figura 6 permite comparar as diferenças de forma, fragmentação e tamanho dos reservatórios de São Domingos e Tucuruí que apresentam valores extremos de FA dentro da Bacia do Rio Tocantins. Fica evidente que o Índice de Desenvolvimento das Margens (D) não captura essas diferenças, uma vez que o coeficiente de variação de D é inferior ao coeficiente de variação das variáveis que lhe dão origem (Área e Perímetro).

Isto sugere que o FA resume em um único número diferentes atributos dos reservatórios de uma determinada bacia, tais como tamanho, direção, grau de desenvolvimento das margens, altura de crista, topografia dominante na bacia de captação, grau de dissecação do relevo e densidade de drenagem. Em contrapartida, o índice D apenas dá alguma informação sobre a forma do reservatório em relação a seu distanciamento de um círculo perfeito. Na figura 7 observa-se o comportamento da média e do desvio padrão de FA e de D para várias bacias hidrográficas brasileiras.

Uma análise geral dos gráficos indica as seguintes tendências: 1) $\mathrm{O}$ índice $\mathrm{D}$ médio é mais uniforme que o índice FA tanto internamente às bacias hidrográficas (pequenos desvios padrão em torno da média), seja entre diferentes bacias (valores médios e desvios padrão variam menos quando comparados ao FA). O índice D Médio varia entre 5, para as bacias do Atlântico Sudeste (que incluem as bacias dos rios Itapemirim, Macaé e Ribeira de Iguape) e 10 para a maioria das bacias. Os valores extremos ocorrem em relação aos reservatórios do Rio Paraná, do Rio Parnaíba, Rio Tocantins e Amazonas. 2)O índice FA médio, no entanto, apresenta grande variabilidade intrabacia hidrográfica, como é o caso das bacias do Atlântico Sudeste que apresentam valores de FA que se

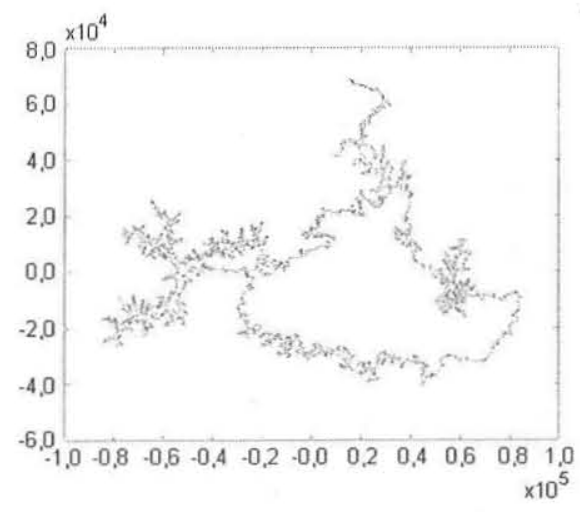

Figura 5-(a) Contorno relativo ao Reservatório de Balbina; (b) como em (a) porém após a rotação dos eixos segundo a direção de máxima variância e aplicação de um filtro do tipo média de 10 pontos. 
Tabela 3 - Média e coeficiente de variação $(C V)$ de D e FA dos reservatórios hidrelétricos agrupados por bacias hidrográficas.

\begin{tabular}{lcc|cc}
\hline \multicolumn{1}{c}{ Bacia hidrográfica } & \multicolumn{2}{c|}{ D } & \multicolumn{2}{c}{ FA(médio) (db) } \\
\hline & Média & $\begin{array}{c}\text { Coeficiente } \\
\text { de Variação }\end{array}$ & Média & $\begin{array}{c}\text { Coeficiente } \\
\text { de Variação }\end{array}$ \\
\hline Atlântico Sudeste & 6,35 & 53,40 & 0,20 & 131,41 \\
Rio Tiete & 8,97 & 48,61 & 0,21 & 54,45 \\
Rio Paranapanema & 8,88 & 51,52 & 0,3 & 38,49 \\
Rio Iguaçu & 10,36 & 45,91 & 0,24 & 47,17 \\
Rio Grande & 7,23 & 58,88 & 0,19 & 73,56 \\
Bacia Lagunar (RS) & 7,64 & 61,74 & 0,27 & 57,43 \\
Rio Paraná (canal principal) & 16,00 & 61,58 & 0,13 & 58,07 \\
Rio Parnaíba & 16,34 & 27,32 & 0,27 & 89,99 \\
Rio Doce & 6,02 & 27,50 & 0,12 & 77,18 \\
Rio São Francisco & 8,95 & 73,04 & 0,24 & 65,14 \\
Rio Paraíba do Sul & 10,34 & 80,00 & 0,28 & 62,87 \\
Rio Tocantins & 18,45 & 60,67 & 0,02 & 1549,75 \\
Rio Amazonas & 18,93 & 42,51 & 0,23 & 28,08 \\
\hline
\end{tabular}

Tucurui

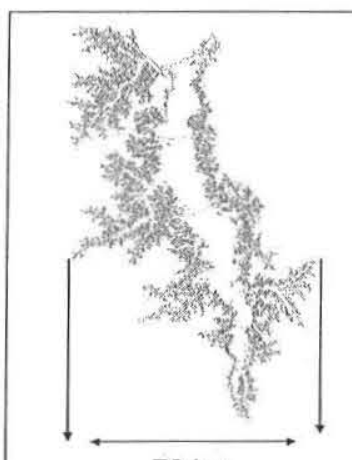

$70 \mathrm{~km}$
São Domingos
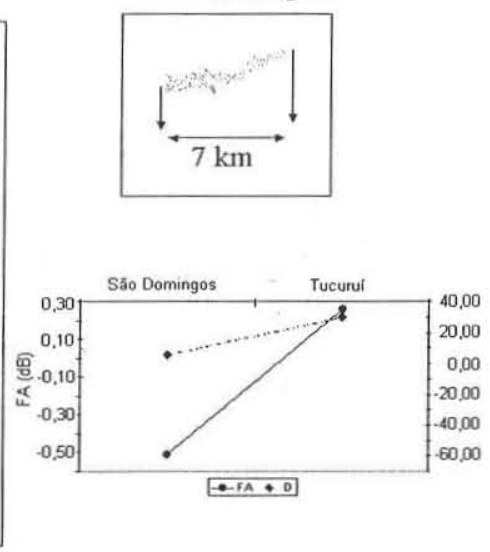

Figura 6 - Configuração Espacial de Reservatórios da bacia do Tocantins. Reservatório de Tucuruí $(F A=0,26 \mathrm{~dB})$, originado a partir da barragem do rio Tocantins. Reservatório de São Domingos $(F A=-0,51 \mathrm{~dB})$, originado a partir da barragem do rio São Domingos, afluente de $2^{\circ}$ ordem do alto curso do rio Tocantins.

estendem de $-0,6$ a 0,57 , indicando que os reservatórios ali presentes apresentam padrões espaciais de pequena até muito grande complexidade.

A análise minuciosa dos reservatórios da Bacia do Rio Ribeira de Iguape (Fig. 8) indica uma grande uniformidade de forma dos reservatórios, condicionada pelo relevo regional. A similaridade das formas dos lagos (ramificados e encaixadas nos vales) explica a pequena variabilidade de D. Observa-se, entretanto, que o tamanho dos reservatórios é bastante distinto. O reservatório de França ocupa uma superfície bem maior do que o reservatório de Serraria, por exemplo. Enquanto o índice D de França é três vezes maior que o de Serraria, o FA destes reservatórios é bastante próximo (Fig. 9)

Quando se observa a figura 9, intuitivamente admite-se que o Reservatório França é mais fragmentado espacialmente que o de Serraria. Isto ocorre porque a avaliação visual do padrão espacial não subtrai o tamanho do reservatório em relação à escala da representação gráfica. Tais reservatórios foram gerados na escala original 1:100 000. Como o tamanho do reservatório de Serraria é três vezes menor do que o de França, a representação gráfica da variabilidade de pequena escala é perdida. Quando os segmentos dos reservatórios são ampliados para escalas maiores, observa-se que em nível de detalhe, os dois reservatórios têm graus de fragmentação semelhantes. Ou seja, descontado o fator dimensional do reservatório, ambos possuem um padrão espacial de baixa complexidade, pouco fragmentado, e com pequena interface com o ecossistema terrestre adjacente, sugerindo menor impacto deste sobre o comportamento físico, químico e biológico do sistema aquático.

O FA, muito mais que o $\mathrm{D}$, representa um indicador de que a Bacia Hidrográfica a que pertence um reservatório não é razão suficiente para definir a complexidade de seu padrão espacial. Em Bacias Hidrográficas que atravessam unidades estruturais diferentes, como é o caso da bacia do Tietê que se desenvolveu superimposta ao contato entre a bacia sedimentar do Paraná e o escudo cristalino, os reservatórios estarão adaptados às características locais da bacia e sua complexidade espacial variará de uma região para outra.

A figura 10 mostra a variação do índice D e do índice FA dos reservatórios hidrelétricos construídos na Bacia do Rio Tietê. Sua análise deixa evidente que os dois índices não co-variam, e que, portanto, revelam propriedades espaciais distintas. Os maiores índices FA e D são apresentados pelos reservatórios de Americana e Três Irmãos, respectivamente. Enquanto que, os menores índices FA e D são apresentados pelos reservatórios de Bariri e de Rasgão, respectivamente.

Na figura 11 pode-se observar as formas dos Reservatórios de Bariri $(F A=-0,06)$ e de Americana $(F A=0,37)$. O Reservatório de Bariri é praticamente encaixado no leito maior do Rio Tietê, exceto pela sua região mais próxima à barragem (ampliada), o que faz com que o valor médio do reservatório seja muito baixo. O Reservatório de Americana, apesar de pequeno, quando comparado ao de Bariri, tem uma forma complexa, com diferentes compartimentos formados por afluentes também alagados pela barragem do rio principal. O valor de $\mathrm{D}$ do reservatório de Americana, entretanto, é muito mais baixo do que o do reservatório de Bariri. O que o índice D informa é que o Reservatório de Bariri apresenta uma forma muito próxima a do canal fluvial do rio que

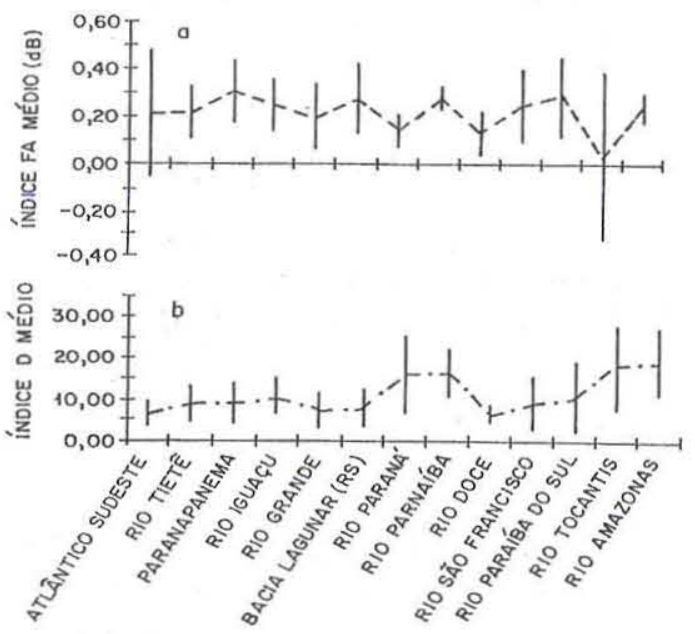

Figura 7 - Média e Desvio Padrão de FA (a) e D (b) dos reservatórios de várias bacias hidrográficas brasileiras. 
(7)

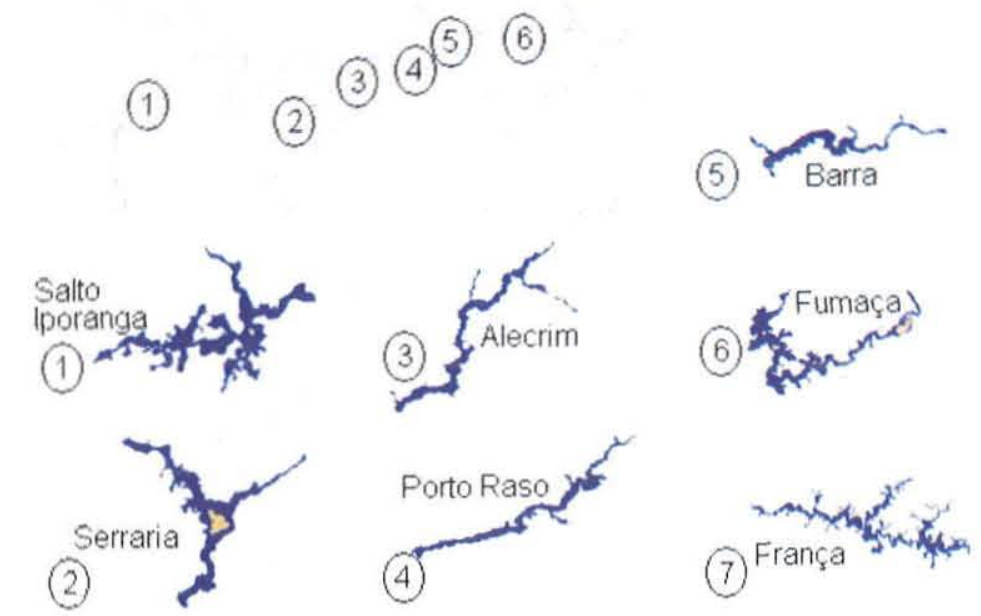

Figura 8-Reservatórios da Bacia do Ribeira de Iguape (Atlântico Sudeste). As áreas em amarelo representam o afloramento de ilhas.

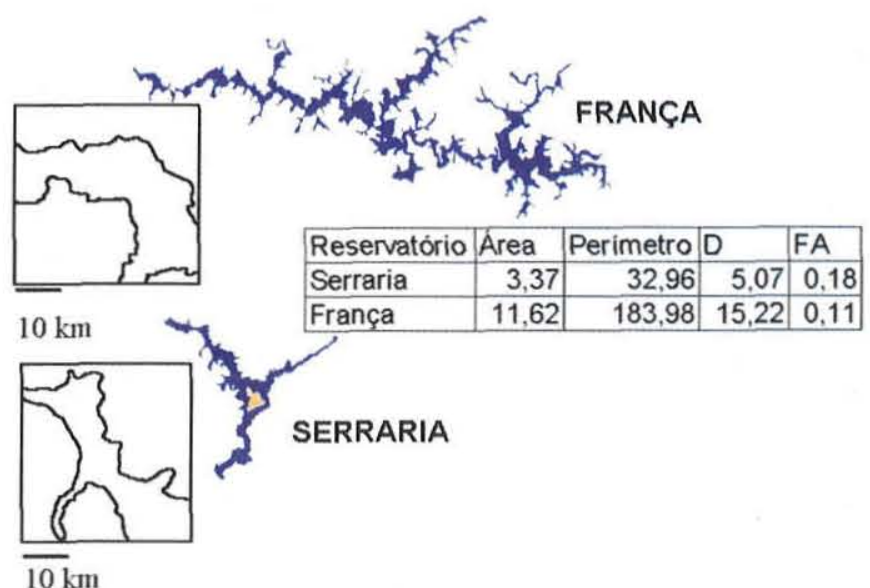

Figura 9-Comportamento de FA e D em reservatórios das bacias do Atlântico Sudeste.

Ihe deu origem, enquanto o de Americana, possui uma forma que se aproxima à de um círculo perfeito.

Relação entre os índices morfométricos (D e FA) e as propriedades limnológicas dos reservatórios Um estudo sobre a tipologia dos reservatórios do Estado de São Paulo (Tundisi 1980) tornou disponível uma série de dados que permitem investigar as relações entre os índices FA e D e algumas propriedades da água. A figura 12 mostra a relação entre os valores de FA e medidas de Produção Primária em alguns reservatórios do Estado de São Paulo selecionados aleatoriamente dos reservatórios estudados por Tundisi (1980). Embora o número de amostras seja limitado, e a relação encontrada não seja estatisticamente significativa, o valor de $\mathrm{r}^{2}$ sugere que o índice de Fragmentação Assimétrica média dos reservatórios contribui, de alguma forma, para a variabilidade da Produtividade Primária dos reservatórios.

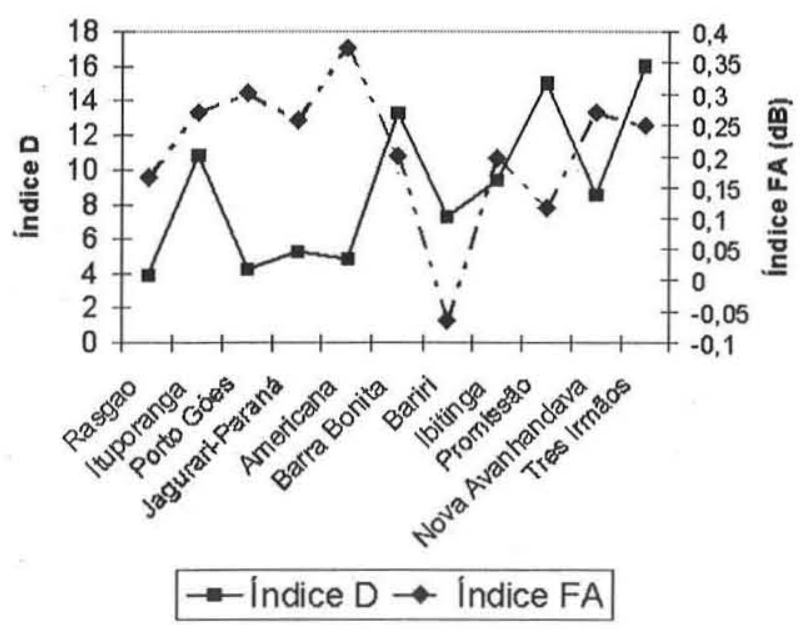

Figura 10 - Variação do índice D e FA dos reservatórios da Bacia do Rio Tietê.

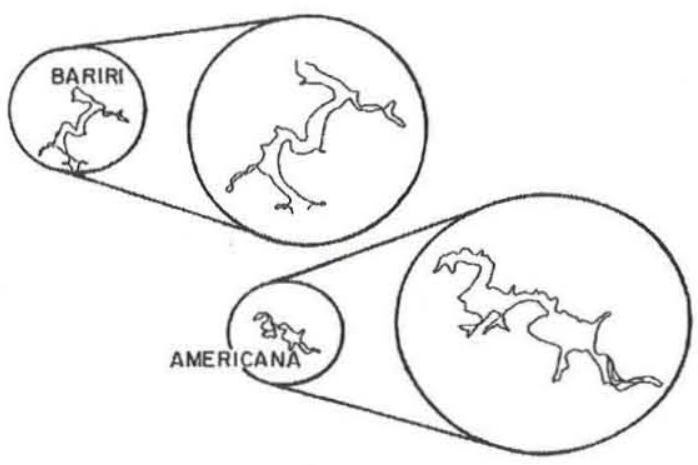

Figura 11 - Variabilidade de FA: forma e tamanho do reservatório 
O gráfico da figura 12 mostra uma tendência de redução da produção primária com o aumento do índice FA, e conseqüentemente, com o aumento da complexidade espacial do reservatório. Isto permite supor que a existência de interfaces complexas (com grandes zonas litorâneas), com aporte de sedimentos através de inúmeros canais marginais, tem um maior impacto sobre o funcionamento do sistema aquático. As extensas zonas litorâneas passam a sustentar comunidades de plantas aquáticas, as quais podem competir ativamente com o fitoplâncton pelos nutrientes e luz disponível para a fotossíntese.

O mesmo conjunto de dados de produção primária, entretanto, não apresenta a mesma relação com o Índice $\mathrm{D}$, como pode ser observado na figura 13

O efeito da superfície inundada sobre o índice de fragmentação assimétrica A área inundada por um reservatório pode afetar o índice de fragmentação assimétrica, mas não é o fator mais relevante. Para testar essa hipótese os reservatórios foram estratificados por tamanho e calculado o coeficiente de correlação linear entre o FA e a área do Reservatório em cada classe (Tabela 4).

A tabela mostra que os coeficientes de correlação não são significativos, e em geral são baixos. As duas classes de tamanho que apresentaram coeficientes mais altos, porém não significativos englobam reservatórios entre 15 e $31 \mathrm{~km}^{2}(0,79)$ e entre 300 e 400 $\mathrm{km}^{2}(0,70)$. A figura 14 mostra os reservatórios que apresentaram alta correlação entre FA e Área. A análise permite verificar que estes reservatórios têm a característica comum de estarem confinados ao leito maior do rio represado.

A posição do reservatório num sistema de cascata e as características topográficas da bacia são fatores muito mais relevantes. Isto pode ser comprovado pela análise da figura 15 , em que se observa um aumento do índice FA com a diminuição da área inundada pelo reservatório. Neste caso específico da Bacia do Médio-Baixo Tietê, o FA está respondendo não apenas à superfície alagada do reservatório, mas à sua posição na cascata, $\mathrm{e}$ conseqüentemente no arcabouço geomorfológico.

O Reservatório de Americana é o menor do conjunto, mas é o que se localiza numa região próxima ao contato entre o Planalto Cristalino e a Depressão Periférica, o que resulta no represamento de um sub-afluente do rio Tietê, o rio Atibaia. Isto produz um padrão de inserção na paisagem mais fragmentado, do que o do reservatório de Promissão, localizado à jusante, já próximo à confluência do rio Tietê com o rio Paraná, onde desenvolve uma ampla planície. Essa distinção não é captada pelo índice D, nem pelo perímetro (que é proporcional à área), mas é bem percebida pelo FA (Fig. 16)

CONCLUSÃO Foi investigada neste trabalho a aplicabilidade do Operador de Fragmentação Assimétrica (FA) na caracterização das propriedades morfométricas dos reservatórios hidrelétricos. A técnica foi aplicada a 124 reservatórios hidrelétricos espalhados pelo Brasil. Os resultados apontaram para vantagens do FA em detectar propriedades morfométricas em relação ao Índice de Desenvolvimento de Margens (D), parâmetro tradicionalmente utilizado pela comunidade de limnólogos.

O parâmetro D, pela sua própria definição, restringe-se apenas à caracterização em relação a quanto os reservatórios aproximamse ou afastam-se da forma geométrica circunferencial. O FA, ao contrário, baseia-se nas propriedades geométricas e estruturais locais ao longo do entorno do reservatório. Isto confere a este parâmetro a capacidade de detectar, em alta resolução, estruturas geomorfológicas que passariam desapercebidas pelo D. Por exemplo, análises baseadas no $\mathrm{D}$ indicaram que os reservatórios da Bacia do Atlântico Sudeste teriam características morfométricas bastante idênticas, fato que foi negado pelo FA. OFA indicou que os reservatórios que compõem esta bacia hidrográfica apresentam padrões espaciais que variam de pouca até muita complexidade, embora tivessem apresentado valores de $\mathrm{D}$ muito próximos entre si.

Pôde-se mostrar também que as inspeções puramente visuais podem levar a confusão quanto à classificação do padrão de

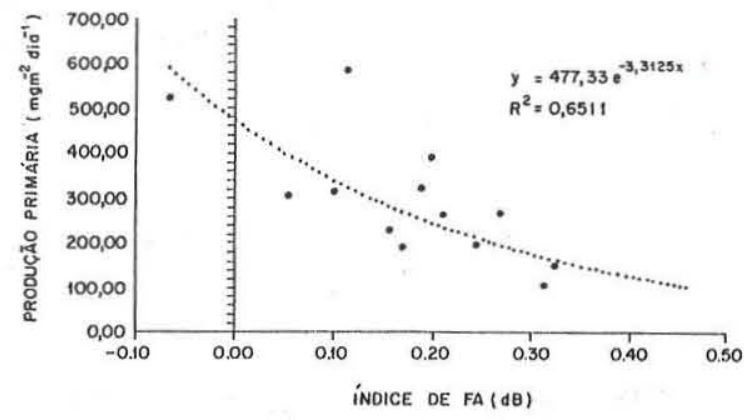

Figura 12 - Relação entre o índice FA e a produção primária fitoplanctônica de reservatórios do Estado de São Paulo.

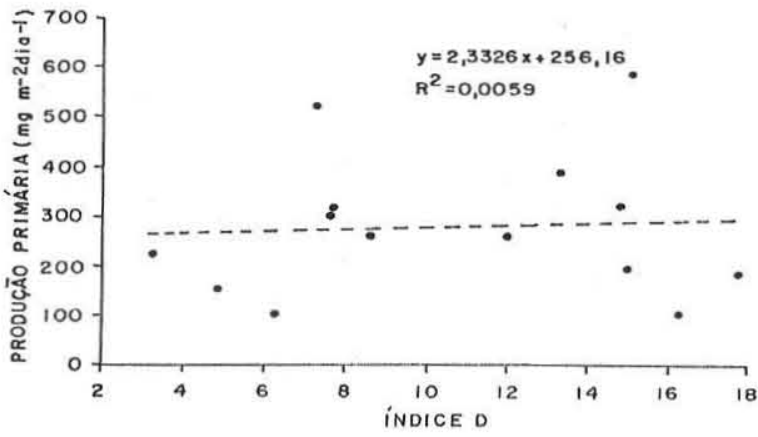

Figura 13 - Produção primária e o índice de desenvolvimento das margens.

Tabela 4 - Coeficiente de correlação entre FA e Área do Reservatório.

\begin{tabular}{lcc}
\hline Classe de tamanho & $\mathrm{r}$ & $\mathrm{N}$ \\
\hline$<1 \mathrm{~km}^{2}$ & 0,01 & 23 \\
$>1<5 \mathrm{~km}^{2}$ & $-0,11$ & 23 \\
$>5<10 \mathrm{~km}^{2}$ & $-0,22$ & 6 \\
$>10<15 \mathrm{~km}^{2}$ & 0,15 & 7 \\
$>15<31 \mathrm{~km}^{2}$ & $-0,79$ & 8 \\
$>31<50 \mathrm{~km}^{2}$ & $-0,17$ & 9 \\
$>50<100 \mathrm{~km}^{2}$ & 0,07 & 10 \\
$>100<200 \mathrm{~km}^{2}$ & 0,59 & 9 \\
$>200<300 \mathrm{~km}^{2}$ & $-0,50$ & 5 \\
$>300<400 \mathrm{~km}^{2}$ & 0,70 & 5 \\
$>400<600 \mathrm{~km}^{2}$ & $-0,35$ & 8 \\
$>600<900 \mathrm{~km}^{2}$ & $-0,62$ & 3 \\
$>900 \mathrm{Km}^{2}$ & $-0,15$ & 8 \\
\hline
\end{tabular}



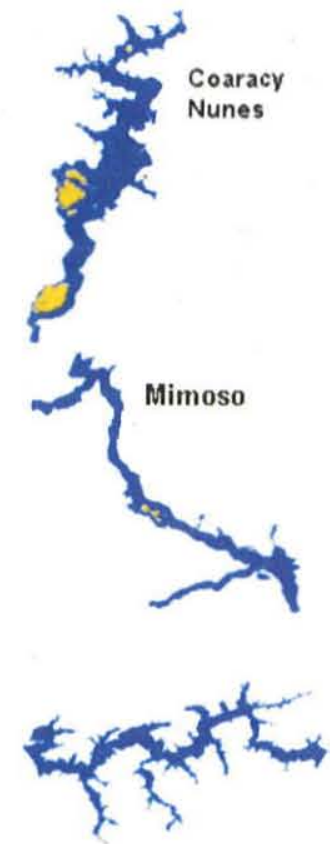

Ituporanga

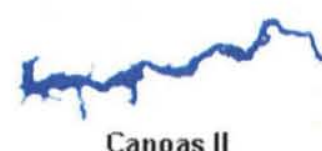

Canoas II
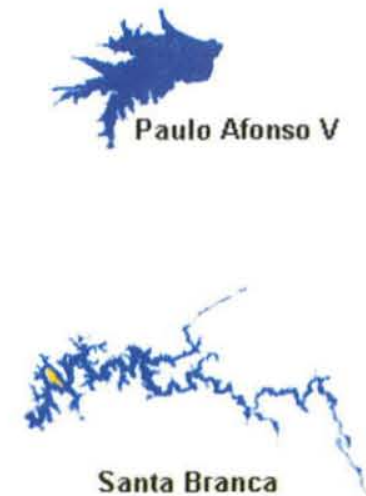

Figura 14 - Reservatórios com alta correlação $(0,79)$ entre FA e área inunda. As áreas em amarelo são ilhas.

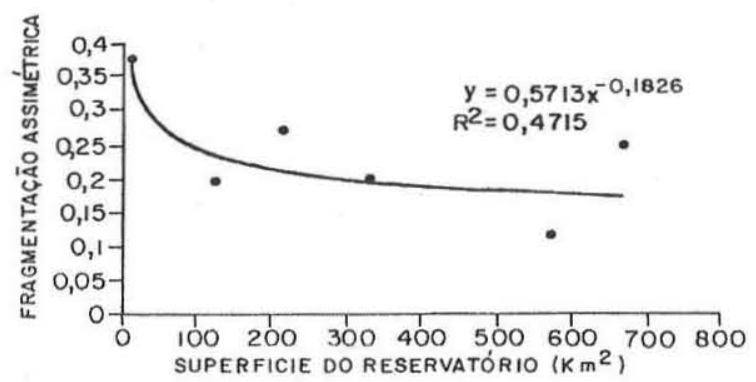

Figura 15-FA em função da superfície alagada dos reservatórios do Baixo Tietê.

morfometria, já que a avaliação visual não leva em conta o tamanho dos reservatórios em relação à escala da representação gráfica. Neste caso o FA funcionaria com uma espécie de classificador automatizado de reservatórios quanto ao nível de complexidade do entorno, e portanto livre da subjetividade da interpretação visual. Em reservatórios que apresentam o entorno muito fragmentado, $o$ índice $\mathrm{D}$, por levar em conta o perímetro do reservatório, tende a ter a sua precisão comprometida.

Análises preliminares indicaram haver relação entre o grau de fragmentação e a produtividade primária nos reservatórios. Embora dependa de uma investigação mais ampla, isto pode ser uma interessante forma de aplicação do FA em Limnologia.

Os resultados indicaram que ao contrário do $\mathrm{D}$, o FA é pouco sensível à área do reservatório, tendo respondido mais a sua posição na cascata, e conseqüentemente ao arcabouço geomorfológico. Um aspecto muito positivo disso é que, em reservatórios que apresentam grande sasonalidade quanto à área inundada, o FA sofreria menos influência se comparado ao $\mathrm{D}$, já que não

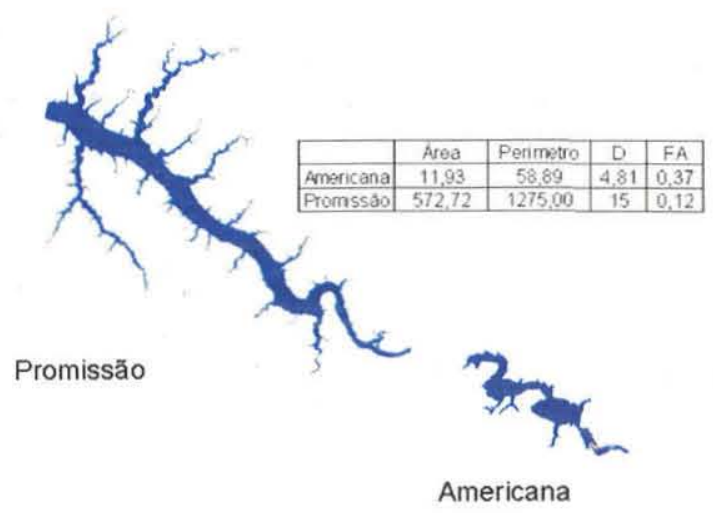

Figura 16 - Relação entre o FA e a posição do reservatório na cascata.

necessariamente a área inundada aumenta proporcional-mente ao perímetro.

Face ao exposto, acredita-se que o FA possa ser um parâmetro útil na caracterização de feições morfométricas de reservatórios, vindo senão a substituir, pelo menos complementar o D nestas atividades.

Agradecimentos À Agencia Nacional de Energia Elétrica (ANEEL) e à Organização Mundial de Meteorologia (OMM) pelo suporte financeiro. À Sra. Ana Lúcia de Castro e ao Sr. Felipe Cota pela elaboração dos desenhos. Aos revisores da RBG pelas sugestões ao manuscrito.

\section{Referências}

Adelsbrunner H. 1993. Handbook of Convex Geometry (eds.) P. M. Gruber and J. M. Wills (Elsevier Science Publishers, 1993), 230 pp.

Assireu A.T., Rosa R.R., Lorenzzetti J.A, Vijaykumar N.L., Rempel E.L., Ramos F.M., Sá L.D.A., Bolzan M.J.A., Zanandrea A. 2002. Gradient pattern analysis of short nonstationary time series: an application to Lagrangian data from satellite tracked drifters. Physica, D, 168-169:397-403.

Christofoletti A. (Eds) 1986. Geomorfologia. São Paulo: Edgard Blücher, $188 \mathrm{pp}$.

Müller A.C. (Eds) 1996. Hidrelétricas, meio ambiente e desenvolvimento. São Paulo: Makron Books, 412 pp.

Rosa R.R., Sharma A.S., Valdivia J.A. 1998. Characterization of localized turbulence in plasma extended system. Physica A, 257:509-514.

Rosa R.R., Sharma A.S., Valdivia J.A. 1999. Characterization of asymmetric fragmentation patterns in spatially extended systems. Intern. J. Modern Physics, C10(1):147-163.

Tundisi J.G. 1980. Tipologia de represas do Estado de São Paulo; relatório. São Carlos:UFSCar.

Wetzel R.T. (Eds) 1975. Limnology. London: W.B. Saunders, 743 pp.

Manuscrito A-1419

Recebido em 10 de março de 2003

Revisão dos autores em 25 de julho de 2004

Revisão aceita em 10 de agosto de 2004 